\title{
NMR analysis and chemical shift calculations of poly(lactic acid) dimer model compounds with different tacticities
}

\begin{abstract}
Koto Suganuma ${ }^{1,2}$, Ken Horiuchi ${ }^{2}$, Hironori Matsuda ${ }^{2}, \mathrm{HN} \mathrm{Cheng}^{3}$, Akihiro Aoki ${ }^{1}$ and Tetsuo Asakura ${ }^{1}$
In this work, poly(lactic acid) (PLA) dimer model compounds with different tacticities were synthesized and studied in detail by ${ }^{1} \mathrm{H}$ and ${ }^{13} \mathrm{C}$ nuclear magnetic resonance (NMR) in three solvents, deuterated chloroform $\left(\mathrm{CDCl}_{3}\right) / \mathrm{CCl}_{4}(20 / 80 \mathrm{v} / \mathrm{v}), \mathrm{CDCl}_{3}$ and dimethyl sulfoxide $-d_{6}$. All of the peaks in the ${ }^{1} \mathrm{H}$ and ${ }^{13} \mathrm{C}$ NMR spectra were assigned with the help of two-dimensional NMR. Although the solvents were different, the tacticity splitting of the dimers showed no significant difference among the solvents. The chemical shifts were calculated and compared with experimental shifts to understand the origin of the tacticity splitting in PLA. Thus, a conformational energy calculation was first performed to determine the energetically stable states in isotactic and syndiotactic dimers by several quantum chemical calculation methods. The ${ }^{1} \mathrm{H}$ and ${ }^{13} \mathrm{C}$ chemical shifts were then calculated for each conformation of the model compounds by considering both the conformational energies of the predominant conformation and the chemical shift of each conformation. The observed tacticity splitting of the chemical shifts between isotactic and syndiotactic ${ }^{1} \mathrm{H}$ and ${ }^{13} \mathrm{C}$ NMR peaks of the dimers was reproduced particularly well, using the combination of Becke's three parameter hybrid method for conformational energy calculations and Hartree-Fock for chemical shift calculations.

Polymer Journal (2012) 44, 838-844; doi:10.1038/pj.2012.106; published online 13 June 2012
\end{abstract}

Keywords: NMR; poly(lactic acid); quantum chemical calculation; stereoregularity

\section{INTRODUCTION}

Poly(lactic acid) (PLA) is a well-known polymer that has been extensively studied. ${ }^{1,2}$ Dimers, trimers and other oligomers of PLA usually occur in concentrated PLA solutions ${ }^{3}$ and are useful materials in their own right, and have also been synthesized through polymerization $^{4-6}$ or degradation. ${ }^{7}$ They can be used as building blocks for functional polymers, for example, oligomer-grafted dextran, ${ }^{8}$ tetrafunctional oligomers ${ }^{9}$ and oligomers encapped with sodium, ${ }^{10}$ acrylates $^{11}$ and isocyanates. ${ }^{12}$ In suitable cases, the oligomers may function as surfactants ${ }^{10}$ and as substitutions for waxes, oils and other petroleum-based oligomers in commercial formulations (Futerro. Lactic acid oligomers. http://www.futerro.com/ products_oligomers.html). In addition, they are useful as model compounds for PLA.

A major determinant of the physical properties of PLA is tacticity. Thus, mechanical properties and heat resistance have been reported to depend on tacticity. ${ }^{13,14}$ Recently, it was shown that tacticity could influence thermal stability, $T_{\mathrm{m}}, T_{\mathrm{g}}$, crystallinity, solution stability and polymer degradability in star-shaped PLA. ${ }^{15,16}$ In addition, poly (L-lactic acid) and poly(D-lactic acid) could form a 1/1 stereocomplex, and the crystalline structure of the stereocomplex was quite different from that of poly(L-lactic acid) or poly(D-lactic acid). ${ }^{17-20}$ It was reported that multiblock copolymers of poly(L-lactic acid) and poly(D-lactic acid) formed the stereocomplex more easily without first forming the single-polymer crystals. ${ }^{21}$ However, PLA with short L- and D-block sequences exhibited relatively a low melting temperature. $^{22}$ Thus, it is important to have detailed information regarding PLA tacticity to understand and improve the polymer's physical properties.

Many nuclear magnetic resonance (NMR) studies of PLA tacticity, including two-dimensional NMR, have been reported using appropriate polymers and model compounds. ${ }^{23-33}$ Most recently, we reported the calculation of ${ }^{1} \mathrm{H}$ and ${ }^{13} \mathrm{C}$ chemical shifts in PLA model compounds. ${ }^{30}$ The ${ }^{1} \mathrm{H}$ and ${ }^{13} \mathrm{C}$ chemical shifts calculated with the quantum chemical method were compared with the observed chemical shifts, and good agreement was obtained for the relative chemical shifts of the ${ }^{1} \mathrm{H}$ and ${ }^{13} \mathrm{C}$ peaks of the $\mathrm{CH}$ group between isotactic and syndiotactic dimer model compounds.

Recent advances in quantum chemical calculations coupled with increases in computer speed and memory size have made it possible to predict the electronic structures of PLA and its model compounds more accurately. ${ }^{34-37}$ Conformational analyses of PLA model compounds were reported ${ }^{38,39}$ using a quantitative method, Becke's three parameter hybrid method (B3LYP)/6-31G $(\mathrm{d}, \mathrm{p})$, for

${ }^{1}$ Department of Biotechnology, Tokyo University of Agriculture and Technology, Koganei, Japan; ${ }^{2}$ Material Analysis Research Laboratories, Teijin Ltd, Hino, Japan and ${ }^{3}$ Southern Regional Research Center, United States Department of Agriculture, Agriculture Research Service, New Orleans, LA, USA

Correspondence: Professor T Asakura, Department of Biotechnology, Tokyo University of Agriculture and Technology, 2-24-16, Nakacho, Koganei, Tokyo 184-8588, Japan. E-mail: asakura@cc.tuat.ac.jp

Received 14 February 2012; revised 5 April 2012; accepted 24 April 2012; published online 13 June 2012 
conformational energy calculations in vacuo or in the electronic environment within the condensed phase. Wu et al. ${ }^{36}$ determined the equilibrium geometries, infra red, total energies and NMR chemical shifts of several lactides, including L-lactide, D-lactide and three mesolactides, using several quantum chemical methods, such as B3LYP/ $6-311+\mathrm{G}(2 \mathrm{~d}, \mathrm{p})$ and B3LYP/6-31G(d). Sadlej et al. ${ }^{40}$ discussed the interaction energies, conformations, vibrational absorption and vibrational circular dichroism spectra for conformers of monomeric chiral D-lactic acid and their complexes with water using B3LYP/augcc-pVDZ and B3LYP/aug-cc-pVTZ.

In this work, the ${ }^{1} \mathrm{H}$ and ${ }^{13} \mathrm{C}$ NMR spectra of isotactic and syndiotactic PLA dimers are observed and assigned by two-dimensional NMR in several solvents to examine the influence of the solvents on tacticity splitting in the ${ }^{1} \mathrm{H}$ and ${ }^{13} \mathrm{C}$ NMR spectra. The chemical shift data in which solvent effects can be ignored are compared with the chemical shifts calculated using several quantum chemical methods. The calculations entail two independent steps using different quantum chemical methods, determining the conformational energy of the preferred conformation first, and then the chemical shifts for each preferred conformation. These calculations are examined with Hartree-Fock (HF) and B3LYP, because HF has been used more commonly in quantum chemical calculations and B3LYP has been used more commonly in density functional calculations. In general, the B3LYP method is effective in the calculation of the electron distribution state for the whole molecule, and HF is effective in calculating the local electron distribution state. The best combination of the quantum chemical methods is selected by virtue of the agreement between the calculated and the observed chemical shifts of the ${ }^{1} \mathrm{H}$ and ${ }^{13} \mathrm{C}$ nuclei of the $\mathrm{CH}$ groups of isotactic and syndiotactic dimer model compounds. The origin of the tacticity splitting in the NMR spectra of PLA is also discussed.

\section{EXPERIMENTAL PROCEDURE}

\section{Synthesis of dimer model compounds (1) of PLA}

The isotactic and syndiotactic dimer model compounds (1) (structure shown in Figure 1) were synthesized from (-)-O-acetyl-L-lactic acid and methyl $S-(-)-$ lactate or $R-(+)$-lactate. The details of the synthesis and purification have been previously described. ${ }^{30}$

\section{NMR measurement}

${ }^{1} \mathrm{H}$ and ${ }^{13} \mathrm{C}$ NMR spectra were obtained on a JEOL $\alpha-600$ spectrometer (JEOL, Tokyo, Japan) operating at $600 \mathrm{MHz}$ and $150 \mathrm{MHz}$, respectively, at room temperature. Deuterated chloroform $\left(\mathrm{CDCl}_{3}\right), 80: 20(\mathrm{v} / \mathrm{v}) \mathrm{CCl}_{4}: \mathrm{CDCl}_{3}$ and dimethyl sulfoxide (DMSO) $-\mathrm{d}_{6}$ were used as solvents, and the sample concentration was $10 \%(\mathrm{w} / \mathrm{v})$. The internal chemical shift reference was tetramethylsilane. The ${ }^{1} \mathrm{H}$ NMR spectra were obtained with a digital resolution of $0.36 \mathrm{~Hz} /$ point with $32 \mathrm{~K}$ data points, together with $45^{\circ}$ flip angle and $4 \mathrm{~s}$ pulse delay. The ${ }^{13} \mathrm{C}$ NMR spectra were obtained with a digital resolution of $1.24 \mathrm{~Hz} /$ point with $32 \mathrm{~K}$ data points, together with a $45^{\circ}$ flip angle and $2 \mathrm{~s}$ pulse delay. ${ }^{1} \mathrm{H}-{ }^{13} \mathrm{C}$ heteronuclear multiple bond correlation (HMBC) spectroscopy was performed using gradient pulse sequences. HMBC spectra were

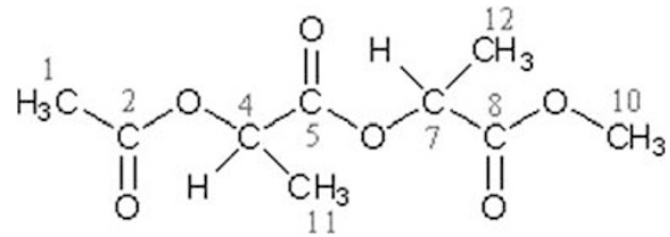

Figure 1 Dimer model compounds (1) of PLA. A full color version of this figure is available at Polymer Journal online. recorded for $7 \mathrm{~h}$ with a $60 \mathrm{~ms}$ delay for long-range ${ }^{1} \mathrm{H}-{ }^{13} \mathrm{C}$ coupling $\left({ }^{2} \mathrm{~J},{ }^{3} \mathrm{~J},{ }^{4} \mathrm{~J}\right)$ selection, with spectral widths of 5.5 p.p.m. for ${ }^{1} \mathrm{H}, 250.0$ p.p.m. for ${ }^{13} \mathrm{C}$ (all peaks), 38.6 p.p.m. for ${ }^{13} \mathrm{C}$ carbonyl or 34.7 p.p.m. for ${ }^{13} \mathrm{C}$ methyl. Before Fourier transformation, the free induction decays were zero-filled twice in the ${ }^{13} \mathrm{C}$ dimension, and a shifted sine bell function was applied to both dimensions.

\section{Conformational energy calculation}

The conformational energy calculation for the monomer model compound was carried out with the Gaussian 09 software program (Gaussian, Pittsburgh, PA, USA) as a function of the internal rotation angle. The quantum chemical method used was HF or B3LYP, ${ }^{41}$ and the basis sets used were $6311+\mathrm{G}^{*},{ }^{42-44}$ TZVP ${ }^{4-47}$ and cc-pVTZ. ${ }^{48-52}$ The conformational energy calculation was also performed for isotactic and syndiotactic dimer model compounds for the preferred conformations selected from the Ramachandran map of the monomer model compound.

\section{Chemical shift calculation}

The magnetic shielding tensor was calculated quantum-chemically according to the GIAO method ${ }^{53-58}$ for ${ }^{1} \mathrm{H}$ and ${ }^{13} \mathrm{C}$ nuclei of the two preferred conformations of the monomer model compound. The HF or B3LYP method was used, and the basis set was $6311+\mathrm{G}^{*}$, TZVP or cc-pVTZ. The isotropic chemical shifts were obtained for comparison with the observed chemical shifts. The ${ }^{1} \mathrm{H}$ and ${ }^{13} \mathrm{C}$ chemical shifts for tetramethylsilane were calculated using the same methods. For the ${ }^{1} \mathrm{H}$ and ${ }^{13} \mathrm{C}$ chemical shift calculations for dimer model compounds, a two-step procedure was used. In each model compound, the relative occurrence probabilities for the preferred conformations were first calculated by Boltzmann distribution, based on the difference in the conformational energies. Because the chemical shifts were calculated for each conformation quantum-chemically, the chemical shifts for each configuration were obtained by taking into account both the relative occurrence probability and the chemical shifts for each conformation.

\section{RESULTS AND DISCUSSION} Assignment of ${ }^{1} \mathrm{H}$ and ${ }^{13} \mathrm{C}$ NMR spectra of PLA dimer model compounds

The ${ }^{1} \mathrm{H}$ and ${ }^{13} \mathrm{C}$ NMR spectra of isotactic and syndiotactic PLA dimer model compounds ( $\mathbf{1}$ ) were first obtained in $\mathrm{CDCl}_{3}$. As expected, the ${ }^{1} \mathrm{H}$ and ${ }^{13} \mathrm{C}$ chemical shift difference between the two $\mathrm{CH}$ groups, 4 and 7 in Figure 1, was very small. The situation was similar for the

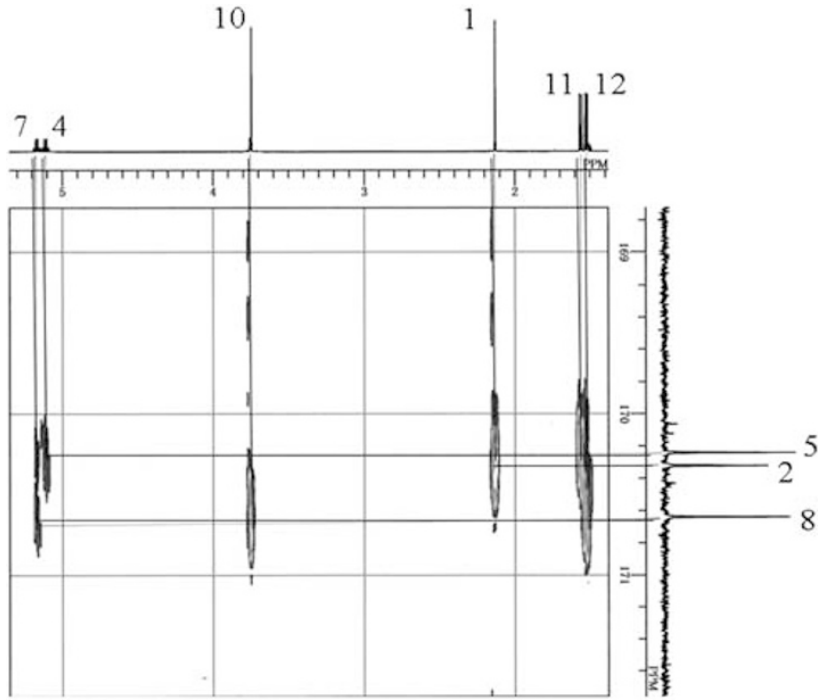

Figure 2 HMBC spectrum of isotactic dimer model compound of PLA in $\mathrm{CDCl}_{3}$, expanded carbonyl region. A full color version of this figure is available at Polymer Journal online. 
two $\mathrm{CH}_{3}$ groups, 11 and 12, in Figure 1. Therefore, it is important to assign these peaks unambiguously. For this purpose, two-dimensional NMR was used, particularly the HMBC experiment, which provides ${ }^{13} \mathrm{C}-{ }^{1} \mathrm{H}$ multiple-bond correlations. The HMBC spectra of isotactic dimer model compound are shown in Figure 2 (carbonyl region), Figure 3 (methyl region) and Figure 4 (entire spectral region).

The peaks from $\mathrm{H}-1, \mathrm{H}-10, \mathrm{C}-1$ and $\mathrm{C}-10$ in Figure 1 were easily identified by their chemical shift values. Thus, the peaks at 2.1 p.p.m. and 20.6 p.p.m. were assigned to $\mathrm{H}-1$ and $\mathrm{C}-1$, and the peaks at 3.7 p.p.m. and 52.3 p.p.m. were assigned to $\mathrm{H}-10$ and $\mathrm{C}-10$, respectively. As shown in Figure 2, C-8 of carbonyl was assigned according to the correlations with $\mathrm{H}-10$, and $\mathrm{C}-2$ of carbonyl was assigned according to the correlations with $\mathrm{H}-1$. Moreover, another carbonyl carbon was assigned to C-5. Two methine protons could be

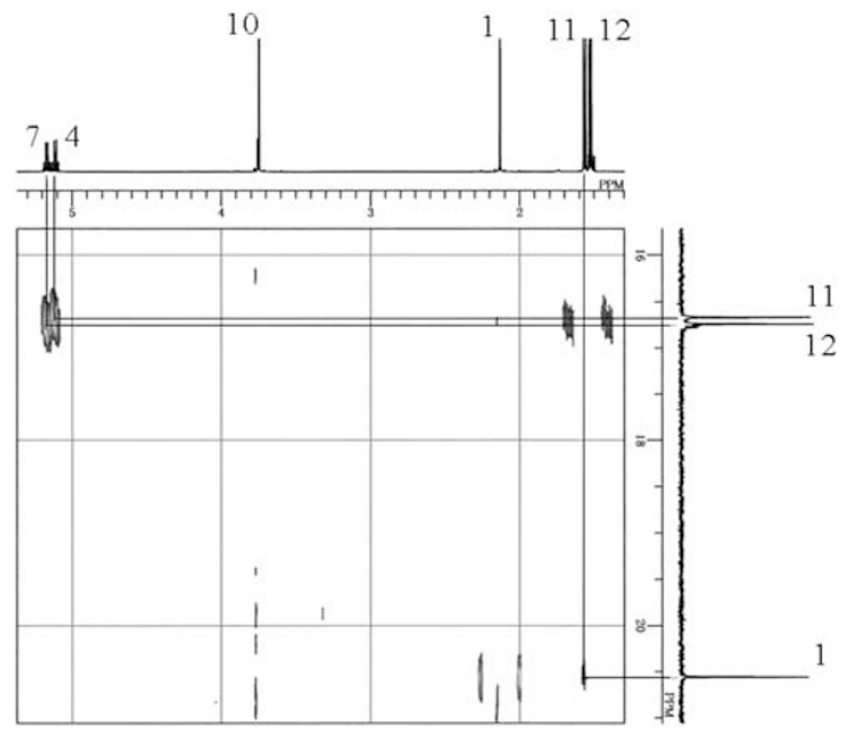

Figure 3 HMBC spectrum of isotactic dimer model compound of PLA in $\mathrm{CDCl}_{3}$, expanded methyl region. A full color version of this figure is available at Polymer Journal online.

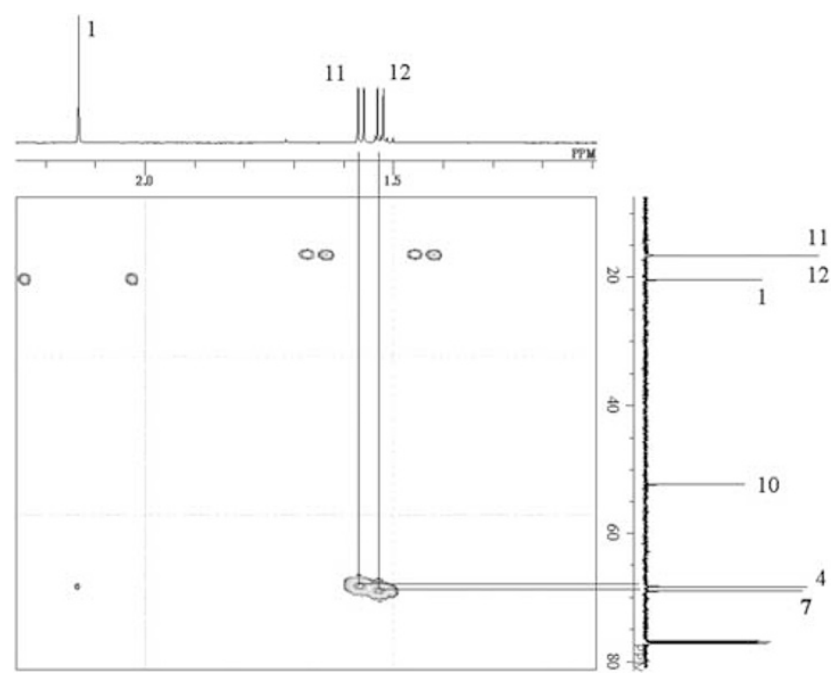

Figure $4 \mathrm{HMBC}$ spectrum of isotactic dimer model compound of PLA in $\mathrm{CDCl}_{3}$, entire spectral region. A full color version of this figure is available at Polymer Journal online. assigned according to the correlations with two carbonyl carbons, H-7 from C-8 and H-4 from C-5. Similarly, two methyl protons could be assigned according to the correlations with two carbonyl carbons, H-11 from C-5 and H-12 from C-8. The assignments of two methyl carbons were made according to the correlations shown in Figure 3. $\mathrm{C}-11$ was assigned according to the correlations with $\mathrm{H}-4$, and $\mathrm{C}-12$ was assigned according to the correlations with H-7. Finally, the assignments of two methine carbons were made according to the correlations shown in Figure 4. C-4 was assigned according to the correlations with $\mathrm{H}-11$, and $\mathrm{C}-7$ was assigned according to the correlations with $\mathrm{H}-12$. Similar assignments were achieved for the syndiotactic dimer model compound using the HMBC spectra (not shown). The chemical shifts and the assignments of the dimer model compounds observed in $\mathrm{CDCl}_{3}$ are summarized in Table 1 .

Table $1{ }^{1} \mathrm{H}$ and ${ }^{13} \mathrm{C}$ chemical shifts (p.p.m. from TMS) of the isotactic and syndiotactic dimer model compounds (1) in several solvents

\begin{tabular}{|c|c|c|c|c|c|c|}
\hline \multirow{2}{*}{$\begin{array}{l}\text { Type } \\
\text { Solvent }\end{array}$} & \multicolumn{3}{|c|}{ Isotactic } & \multicolumn{3}{|c|}{ Syndiotactic } \\
\hline & $\begin{array}{l}\mathrm{CDCl}_{3} / \mathrm{CCl}_{4} \\
(20 / 80 \mathrm{~V} / \mathrm{V})\end{array}$ & $\mathrm{CDCl}_{3}$ & DMSO- $d_{6}$ & $\begin{array}{l}\mathrm{CDCl}_{3} / \mathrm{CCl}_{4} \\
(20 / 80 \mathrm{~V} / \mathrm{V})\end{array}$ & $\mathrm{CDCl}_{3}$ & $D M S O-d_{6}$ \\
\hline \multicolumn{7}{|l|}{${ }^{1} \mathrm{H}$} \\
\hline 1 & 2.08 & 2.13 & 2.07 & 2.08 & 2.13 & 2.08 \\
\hline 10 & 3.72 & 3.75 & 3.68 & 3.72 & 3.76 & 3.68 \\
\hline 4 & 4.99 & 5.11 & 5.05 & 5.05 & 5.16 & 5.08 \\
\hline 7 & 5.1 & 5.17 & 5.12 & 5.05 & 5.15 & 5.06 \\
\hline 11 & 1.52 & 1.57 & 1.46 & 1.49 & 1.53 & 1.44 \\
\hline 12 & 1.5 & 1.53 & 1.44 & 1.47 & 1.51 & 1.42 \\
\hline \multicolumn{7}{|l|}{${ }^{13} \mathrm{C}$} \\
\hline 1 & 20.21 & 20.55 & 20.27 & 20.23 & 20.56 & 20.29 \\
\hline 10 & 51.91 & 52.32 & 52.29 & 51.94 & 52.38 & 52.23 \\
\hline 4 & 68.01 & 68.3 & 68.04 & 68.17 & 68.44 & 68.2 \\
\hline 7 & 68.56 & 69 & 68.95 & 68.81 & 69.14 & 69.09 \\
\hline 11 & 16.54 & 16.68 & 16.52 & 16.64 & 16.77 & 16.58 \\
\hline 12 & 16.65 & 16.75 & 16.56 & 16.65 & 16.8 & 16.61 \\
\hline 2 & 169.53 & 170.33 & 170.05 & 169.35 & 170.14 & 169.87 \\
\hline 5 & 169.26 & 170.24 & 169.87 & 169.12 & 170.08 & 169.82 \\
\hline 8 & 169.99 & 170.65 & 170.39 & 169.78 & 170.44 & 170.29 \\
\hline
\end{tabular}

Abbreviations: $\mathrm{CDCl}_{3}$, deuterated chloroform; DMSO, dimethyl sulfoxide; TMS, tetramethylsilane.

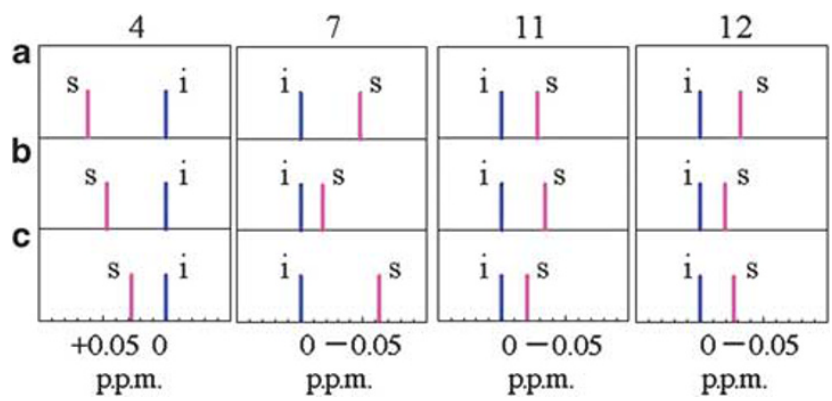

Figure 5 Comparison of the observed ${ }^{1} \mathrm{H}$ chemical shifts (in p.p.m.) of PLA dimer model compound (1) shown as stick spectra. The solvents are (a) $\mathrm{CDCl}_{3} / \mathrm{CCl}_{4}(20 / 80 \mathrm{v} / \mathrm{v})$, (b) $\mathrm{CDCl}_{3}$ and (c) DMSO- $\mathrm{d}_{6}$. The chemical shifts are shown relative to the isotactic chemical shift. The blue stick corresponds to isotactic (i) and the pink stick to syndiotactic (s). 
Effects of different solvents on the relative chemical shifts between isotactic and syndiotactic dimer model compounds

In the past, $\mathrm{CDCl}_{3}$ and DMSO- $\mathrm{d}_{6}$ were often used as NMR solvents for PLA. To compare the calculated and the observed chemical shifts, especially for tacticity splitting, the solvent effect should be minimized as much as possible, because chemical shift calculations are generally

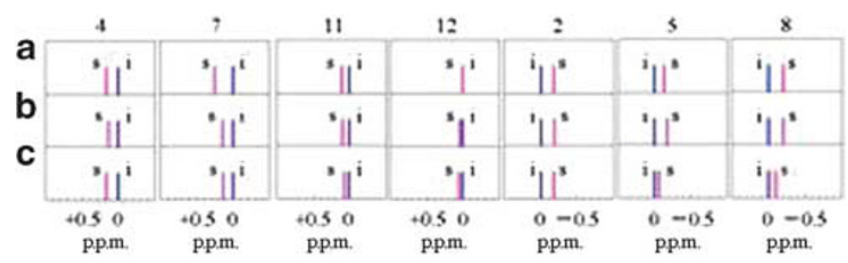

Figure 6 Comparison of the observed ${ }^{13} \mathrm{C}$ chemical shifts (in p.p.m.) of PLA dimer model compound (1) shown as stick spectra. The solvents are (a) $\mathrm{CDCl}_{3} / \mathrm{CCl}_{4}(2 \mathrm{O} / 80 \mathrm{v} / \mathrm{v})$, (b) $\mathrm{CDCl}_{3}$ and (c) DMSO- $\mathrm{d}_{6}$. The chemical shifts are shown relative to the isotactic chemical shift. The blue stick corresponds to isotactic (i) and the pink stick to syndiotactic (s).

Table 2 The occurrence probabilities (\%) of preferred conformations of dimer model compounds (1)

\begin{tabular}{|c|c|c|c|c|c|c|c|c|c|}
\hline \multicolumn{2}{|c|}{ Type } & \multicolumn{4}{|c|}{ Isotactic } & \multicolumn{4}{|c|}{ Syndiotactic } \\
\hline Method & Basis set & LIL1 & L1L2 & L2L1 & L2L2 & $L 2 D 1$ & L1D2 & $L 1 D 1$ & L2D2 \\
\hline B3LYP & TZVP & 77.31 & 17.51 & 3.1 & 2.08 & 45.08 & 30.64 & 12.96 & 11.33 \\
\hline $\mathrm{HF}$ & TZVP & 86.3 & 12.16 & 0.83 & 0.7 & 52.48 & 28.91 & 10.63 & 7.98 \\
\hline B3LYP & cc-pVTZ & 76.79 & 17.09 & 3.19 & 2.92 & 46.84 & 30.25 & 10.75 & 12.16 \\
\hline $\mathrm{HF}$ & cc-pVTZ & 84.79 & 13.1 & 0.91 & 1.2 & 53.85 & 28.23 & 8.3 & 9.61 \\
\hline B3LYP & $6311+\mathrm{G}^{*}$ & 76.27 & 17.98 & 3.28 & 2.47 & 47.5 & 28.59 & 11.55 & 12.35 \\
\hline $\mathrm{HF}$ & $6311+G^{*}$ & 84.13 & 13.9 & 0.87 & 1.11 & 53.87 & 27.82 & 8.73 & 9.58 \\
\hline
\end{tabular}

performed on molecules in vacuo. It is well known that $\mathrm{CDCl}_{3}$ is a polar solvent. It would be desirable to verify the effects of a less polar solvent and a more polar solvent on the relative chemical shifts between isotactic and syndiotactic dimer model compounds. DMSO- $\mathrm{d}_{6}$ was selected because it is more polar than $\mathrm{CDCl}_{3}$. A suitable non-polar solvent is $\mathrm{CCl}_{4}$. PLA is insoluble, but the dimer model compounds are soluble in $\mathrm{CCl}_{4}$. Thus, the solvent mixture $\mathrm{CCl}_{4} / \mathrm{CDCl}_{3}(20 \% \mathrm{v} / \mathrm{v})$ was chosen, with $20 \% \mathrm{CDCl}_{3}$ added for ${ }^{2} \mathrm{H}$ field locking. For both of these solvents, unambiguous assignments were again required because of the small chemical shift differences between two $\mathrm{CH}$ groups and between two $\mathrm{CH}_{3}$ groups in the dimer model compounds. The $\mathrm{HMBC}$ experiment was again conducted. The results for $\mathrm{CDCl}_{3} / \mathrm{CCl}_{4}$ $(20 / 80 \mathrm{v} / \mathrm{v})$ and DMSO- $\mathrm{d}_{6}$ solvents are also presented in Table 1.

For ease of presentation, the observed chemical shifts for all ${ }^{1} \mathrm{H}$ and ${ }^{13} \mathrm{C}$ peaks of the dimer model compounds, except for those of two terminal $\mathrm{CH}_{3}$ groups, are shown as stick spectra in Figures 5 and 6 , respectively.

Note that the observed chemical shift differences are indeed very small between the isotactic and syndiotactic dimer model compounds for both ${ }^{1} \mathrm{H}$ and ${ }^{13} \mathrm{C}$ nuclei. However, there was no reversal of isotactic/syndiotactic assignments in different solvents. Moreover, there was no obvious trend between the chemical shift difference and solvent polarity. Thus, we can use the chemical shifts observed in $\mathrm{CDCl}_{3} / \mathrm{CCl}_{4}$ for comparison with the calculated chemical shifts.

\section{Conformational energy calculations of the dimer model compounds (1)}

The four energetically stable states generated from the combination of two preferred conformations in the Ramachandran conformational energy map of the monomer model compound ${ }^{30}$ were the initial four preferred conformations of the dimer model compounds (1). The

Table $3{ }^{1} \mathrm{H}$ and ${ }^{13} \mathrm{C}$ chemical shifts (p.p.m. from TMS) of the isotactic dimer model compound (1) together with probability (\%) of each conformation and observed chemical shifts in $\mathrm{CDCl}_{3} / \mathrm{CCl}_{4}(20 / 80 \mathrm{v} / \mathrm{v})$

\begin{tabular}{|c|c|c|c|c|c|c|c|c|c|c|}
\hline \multirow{3}{*}{$\begin{array}{l}\text { Type } \\
\text { Code }\end{array}$} & \multicolumn{10}{|c|}{ isotactic } \\
\hline & \multicolumn{9}{|c|}{ Calculated } & \multirow{2}{*}{$\begin{array}{c}\text { Observed } \\
\text { (j) }\end{array}$} \\
\hline & (a) & (b) & (c) & (d) & (e) & $(f)$ & (g) & (h) & (i) & \\
\hline \multirow{4}{*}{$\begin{array}{l}\text { Method and basis set of } \\
\text { conformational optimization } \\
\text { Method and basis set of } \\
\text { calculation of chemical shifts }\end{array}$} & B3LYP & B3LYP & HF TZVP & B3LYP & B3LYP & HF cc-pVTZ & B3LYP & B3LYP & $\mathrm{HF}$ & \multirow{4}{*}{$\begin{array}{l}\mathrm{CDCl}_{3} / \mathrm{CCl}_{4} \\
(20 / 80 \mathrm{v} / \mathrm{v})\end{array}$} \\
\hline & TZVP & TZVP & & cc-pVTZ & cc-pVTZ & & $6311+\mathrm{G}^{*}$ & $6311+\mathrm{G}^{*}$ & $6311+\mathrm{G}^{*}$ & \\
\hline & HF TZVP & B3LYP & HF TZVP & HF cc-pVTZ & B3LYP & HF cc-pVTZ & HF & B3LYP & HF & \\
\hline & & TZVP & & & cc-pVTZ & & $6311+\mathrm{G}^{*}$ & $6311+\mathrm{G}^{*}$ & $6311+\mathrm{G}^{*}$ & \\
\hline \multicolumn{11}{|l|}{${ }^{1} H$} \\
\hline 4 & 4.48 & 4.84 & 4.28 & 5.14 & 5.55 & 4.98 & 4.71 & 4.99 & 4.53 & 4.99 \\
\hline 7 & 4.57 & 4.92 & 4.32 & 5.26 & 5.65 & 5.05 & 4.76 & 5.02 & 4.55 & 5.1 \\
\hline 11 & 1.56 & 1.52 & 1.51 & 2.02 & 2.01 & 2.01 & 1.62 & 1.56 & 1.58 & 1.52 \\
\hline 12 & 1.46 & 1.43 & 1.39 & 1.94 & 1.94 & 1.92 & 1.53 & 1.49 & 1.47 & 1.5 \\
\hline \multicolumn{11}{|l|}{${ }^{13} \mathrm{C}$} \\
\hline 4 & 65.96 & 73.47 & 62.65 & 66.83 & 73.94 & 63.99 & 66.21 & 73.87 & 63.02 & 68.01 \\
\hline 7 & 65.46 & 73.12 & 62.13 & 66.52 & 73.13 & 63.57 & 66.19 & 73.95 & 62.79 & 68.56 \\
\hline 11 & 16.63 & 17.94 & 16.79 & 17.19 & 18.45 & 17.53 & 17.27 & 18.83 & 17.45 & 16.54 \\
\hline 12 & 16.63 & 17.95 & 16.75 & 17.14 & 18.24 & 17.49 & 17.42 & 18.94 & 17.59 & 16.65 \\
\hline 2 & 182.84 & 177.73 & 174.98 & 180.05 & 176.27 & 173.18 & 180.4 & 177.58 & 173.23 & 169.53 \\
\hline 5 & 182.79 & 179.28 & 175.35 & 180.44 & 178.03 & 173.92 & 180 & 178.46 & 173.25 & 169.26 \\
\hline 8 & 183.56 & 180.05 & 176.11 & 181.04 & 178.9 & 174.47 & 180.6 & 179.22 & 173.79 & 169.99 \\
\hline
\end{tabular}

Abbreviations: $\mathrm{CDCl}_{3}$, deuterated chloroform; TMS, tetramethylsilane. 
Table $4{ }^{1} \mathrm{H}$ and ${ }^{13} \mathrm{C}$ chemical shifts (p.p.m. from TMS) of the syndiotactic dimer model compound (1) together with probability (\%) of each conformation and observed chemical shifts in $\mathrm{CDCl}_{3} / \mathrm{CCl}_{4}(20 / 80 \mathrm{v} / \mathrm{v})$

\begin{tabular}{|c|c|c|c|c|c|c|c|c|c|c|}
\hline \multirow{3}{*}{$\begin{array}{l}\text { Type } \\
\text { Code }\end{array}$} & \multicolumn{10}{|c|}{ Syndiotactic } \\
\hline & \multicolumn{9}{|c|}{ Calculated } & \multirow{2}{*}{$\frac{\text { Observed }}{\text { (j) }}$} \\
\hline & (a) & (b) & (C) & (d) & (e) & $(f)$ & (g) & $(h)$ & (i) & \\
\hline $\begin{array}{l}\text { Method and basis set of } \\
\text { conformational optimization }\end{array}$ & $\begin{array}{l}\text { B3LYP } \\
\text { TZVP }\end{array}$ & $\begin{array}{l}\text { B3LYP } \\
\text { TZVP }\end{array}$ & HF TZVP & $\begin{array}{l}\text { B3LYP } \\
\text { cc-pVTZ }\end{array}$ & $\begin{array}{l}\text { B3LYP } \\
\text { cc-pVTZ }\end{array}$ & $\begin{array}{c}\mathrm{HF} \\
\text { cc-pVTZ }\end{array}$ & $\begin{array}{c}\text { B3LYP } \\
6311+G^{*}\end{array}$ & $\begin{array}{c}\text { B3LYP } \\
6311+G^{*}\end{array}$ & $\begin{array}{c}\mathrm{HF} \\
6311+\mathrm{G}^{*}\end{array}$ & $\mathrm{CDCl}_{3} / \mathrm{CCl}_{4}$ \\
\hline $\begin{array}{l}\text { Method and basis set of } \\
\text { calculation of chemical shifts }\end{array}$ & HF TZVP & $\begin{array}{l}\text { B3LYP } \\
\text { TZVP }\end{array}$ & HF TZVP & HF cc-pVTZ & $\begin{array}{l}\text { B3LYP } \\
\text { cc-pVTZ }\end{array}$ & $\begin{array}{c}\mathrm{HF} \\
\text { cc-pVTZ }\end{array}$ & $\begin{array}{c}H F \\
6311+G^{*}\end{array}$ & $\begin{array}{c}\text { B3LYP } \\
6311+\mathrm{G}^{*}\end{array}$ & $\begin{array}{c}\mathrm{HF} \\
6311+\mathrm{G}^{*}\end{array}$ & $(20 / 80 \mathrm{v} / \mathrm{v})$ \\
\hline \multicolumn{11}{|l|}{${ }^{1} \mathrm{H}$} \\
\hline 4 & 4.52 & 4.81 & 4.24 & 5.18 & 5.45 & 4.95 & 4.73 & 4.9 & 4.49 & 5.05 \\
\hline 7 & 4.51 & 4.84 & 4.25 & 5.2 & 5.55 & 4.97 & 4.71 & 4.92 & 4.48 & 5.05 \\
\hline 11 & 1.5 & 1.48 & 1.45 & 1.97 & 1.97 & 1.96 & 1.58 & 1.54 & 1.53 & 1.49 \\
\hline 12 & 1.39 & 1.39 & 1.35 & 1.91 & 1.9 & 1.88 & 1.48 & 1.44 & 1.42 & 1.47 \\
\hline \multicolumn{11}{|l|}{${ }^{13} \mathrm{C}$} \\
\hline 4 & 66.22 & 75.12 & 63.52 & 67.85 & 75.44 & 65.55 & 67.13 & 75.51 & 64.5 & 68.17 \\
\hline 7 & 66.09 & 73.12 & 62.76 & 66.83 & 73.61 & 63.72 & 66.37 & 74.08 & 62.87 & 68.81 \\
\hline 11 & 17.05 & 18.16 & 17.1 & 17.59 & 18.6 & 17.91 & 17.61 & 19.05 & 17.71 & 16.64 \\
\hline 12 & 16.58 & 17.99 & 16.68 & 17.14 & 18.28 & 17.41 & 17.47 & 18.96 & 17.56 & 16.65 \\
\hline 2 & 182.8 & 177.59 & 174.99 & 180.02 & 176.23 & 173.2 & 180.39 & 177.49 & 173.28 & 169.35 \\
\hline 5 & 182.68 & 178.46 & 175.19 & 180.35 & 177.47 & 173.78 & 180 & 177.95 & 173.26 & 169.12 \\
\hline 8 & 183.28 & 179.45 & 175.83 & 180.8 & 178.37 & 174.24 & 180.33 & 178.87 & 173.57 & 169.78 \\
\hline
\end{tabular}

Abbreviations: $\mathrm{CDCl}_{3}$, deuterated chloroform; TMS, tetramethylsilane.

D-isomer of syndiotactic dimer model was derived by flipping the sign of the $Z$-coordinate of the $X-Y-Z$ coordinates. The conformational energies of four conformations for each isotactic and syndiotactic dimer model compound (1) were optimized by two quantum chemical methods, B3LYP and HF, with different basis sets, that is, TZVP, cc-pVTZ and $6300+\mathrm{G}^{*}$. The relative occurrence probabilities of the preferred conformations were calculated using a Boltzmann distribution and the difference in the conformational energies after optimization, as shown in Table 2 . Here, the number ' 1 ' indicates the most stable conformation in the Ramachandran conformational energy map of the monomer model compound, and the number ' 2 ' indicates the second most stable conformation.

There is no abnormal trend among the occurrence probabilities of the preferred conformations calculated by different quantum chemical methods and different basis sets. However, there are significant differences between the values calculated by the B3LYP and HF methods. These differences seem to arise from the approximations used in the quantum chemical methods, because B3LYP includes electron correlation, but HF does not.

${ }^{1} \mathrm{H}$ and ${ }^{13} \mathrm{C}$ chemical shift calculations of dimer model compounds (1) and comparison between the calculated and observed chemical shifts

The ${ }^{1} \mathrm{H}$ and ${ }^{13} \mathrm{C}$ chemical shifts of each conformation of the dimer model compounds (1) were calculated and averaged by the occurrence probabilities. The chemical shifts of all ${ }^{1} \mathrm{H}$ and ${ }^{13} \mathrm{C}$ nuclei, except for those of two terminal $\mathrm{CH}_{3}$ groups, are listed in Table 3 (isotactic) and Table 4 (syndiotactic), together with the observed chemical shifts in $\mathrm{CDCl}_{3} / \mathrm{CCl}_{4}(20 / 80 \mathrm{v} / \mathrm{v})$.

The calculated and observed ${ }^{1} \mathrm{H}$ and ${ }^{13} \mathrm{C}$ chemical shifts are shown as stick spectra in Figures 7 and 8, respectively.

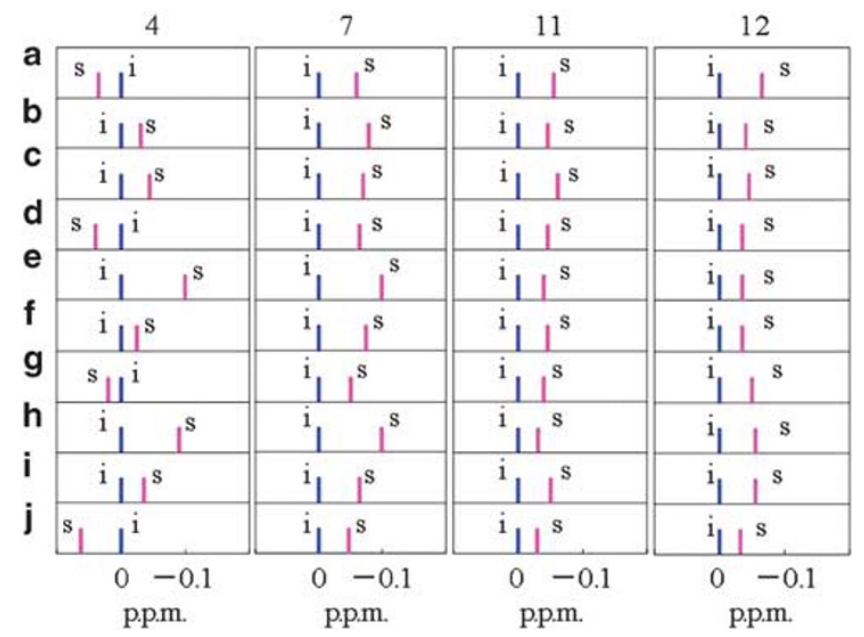

Figure 7 Comparison of calculated and observed ${ }^{1} \mathrm{H}$ chemical shifts (in p.p.m.) of PLA dimer model compounds (1) shown as stick spectra. (a-i) represent the calculated chemical shift, (j) represents the observed chemical shift. The identity of each code is presented in row 3 of Tables 3 and 4 . The chemical shifts are shown relative to the isotactic chemical shift. The blue stick corresponds to isotactic and the pink stick to syndiotactic.

Except for H-4, good agreement can be seen between the observed and calculated chemical shifts for the relative chemical shifts of the isotactic and syndiotactic ${ }^{1} \mathrm{H}$ and ${ }^{13} \mathrm{C}$ NMR peaks of the dimer model compounds, irrespective of the quantum chemical methods or the basis sets. For H-4, the observed syndiotactic peak appears downfield from the isotactic peak, and this trend agrees with calculation codes (a), (d) and (g) in Figure 7. In these three calculations, (a), (d) and 


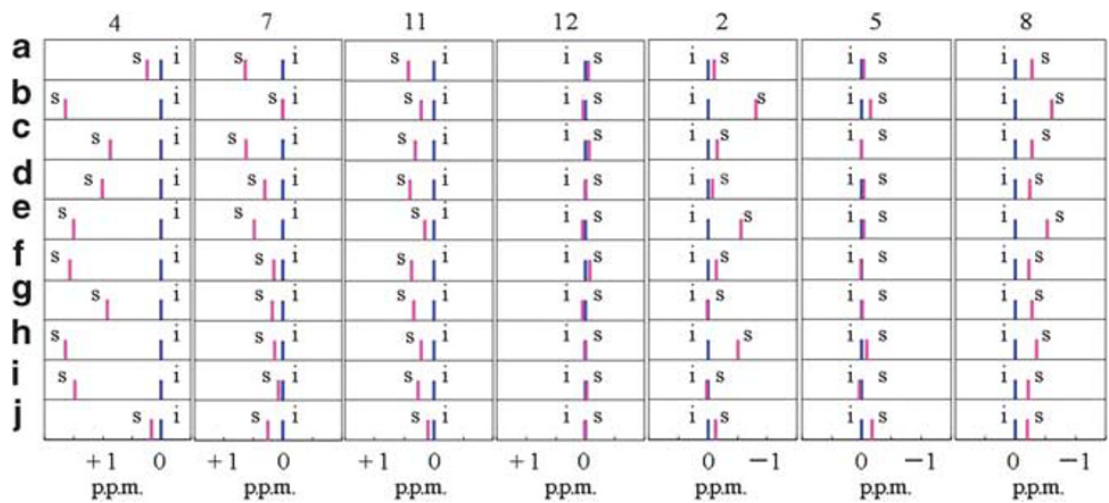

Figure 8 Comparison of the calculated and observed ${ }^{13} \mathrm{C}$ chemical shifts (in p.p.m.) of PLA dimer model compounds (1) shown as stick spectra. (a-i) represent the calculated chemical shift, (j) represents the observed chemical shift. The identity of each code is shown in row 3 of Tables 3 and 4 . The chemical shifts are shown relative to the isotactic chemical shift. The blue stick corresponds to isotactic and the pink stick to syndiotactic.

(g), the method used to perform conformational optimization was B3LYP, and the method used to perform the chemical shift calculations of the preferred conformation was HF, although the basis sets were different. In general, the B3LYP method is effective in calculating the electron distribution state for the whole molecule, and HF is effective in calculating the local electron distribution state in the neighborhood of nuclei of interest. For H-4, the calculation codes (b), (e) and (h) in Figure 7 do not agree with the observed chemical shift. This discrepancy occurred because tacticity splitting in the NMR spectra depends on not only the electron distribution state in the whole molecule, but also the local electron distribution state. Similar reasoning applied to the calculation codes (c), (f) and (i) in Figure 7. Conformation depends on the electron distribution state in the whole molecule, and the chemical shift depends on the local electron distribution state in the neighborhood of nuclei of interest. Thus, B3LYP is preferred for conformational optimization, and $\mathrm{HF}$ is preferred for the chemical shift calculation. Note that B3LYP includes electron correlation in the calculation but only approximates it. Even better results would likely be obtained if the electron correlation were calculated exactly without resorting to approximations, but the computation time needed would be prohibitive. Moreover, the considerations made regarding the calculation methods used are not confined to the case of PLA. It is likely that the combination of HF and B3LYP, rather than the use of each method by itself, would also be preferred in studying other compounds.

In summary, satisfactory results for the calculated shifts of different tacticities of PLA dimer have been obtained in a comparatively short time by combining B3LYP with HF methods. The calculations suggest that the different electronic environments of ${ }^{1} \mathrm{H}$ and ${ }^{13} \mathrm{C}$ nuclei, their electron correlations and the conformation of the molecules contribute to the tacticity splitting in the NMR spectra of PLA and the PLA dimer model compounds.

\section{ACKNOWLEDGEMENTS}

T.A. acknowledges support from a Grant-in-Aid for Scientific Research from the Ministry of Education, Science, Culture and Supports of Japan (23245045) and (21550112). We thank Mr Masato Komiyama at Teijin Pharma Ltd for his support on the synthesis of the model compounds and Dr Masao Hirasaka at Teijin Ltd for useful discussions. Mention of trade names or commercial products in this publication is solely for the purpose of providing specific information and does not imply recommendation or endorsement by the US Department of Agriculture; the USDA is an equal opportunity provider and employer.
1 Södergård, A. \& Stolt, M. Properties of lactic acid based polymers and their correlation with composition. Prog. Polym. Sci. 27, 1123-1163 (2002).

2 Garlotta, D. A literature review of poly(lactic acid). J. Polym. Environ. 9, 63-84 (2001).

3 Filachione, E.M. \& Fisher, C.H. Lactic acid condensation polymers. Ind. Eng. Chem 36, 223-228 (1944).

4 de Jong, S.J., van Dijk-Wolthuis, W.N.E., Kettenes-van den Bosch, J.J., Schuyl, PJ.W. \& Hennink, W.E. Monodisperse enantiomeric lactic acid oligomers: Preparation, characterization, and stereocomplex formation. Macromolecules 31, 6397-6402 (1998).

5 Schliecker, G., Schmidt, C., Fuchs, S. \& Kissel, T. Characterization of a homologous series of D,L-lactic acid oligomers; a mechanistic study on the degradation kinetics in vitro. Biomaterials 24, 3835-3844 (2003).

6 Kaitian, X., Kozluca, A., Denkbas, E.B. \& Piskin, E. Poly(D,L-lactic acid) homopolymers: Synthesis and characterization. Tr. J. Chem. 20, 43-53 (1996).

7 Okamoto, K., Toshima, K. \& Matsumura, S Degradation of poly(lactic acid) into repolymerizable oligomer using montmorillonite K10 for chemical recycling. Macromol. Biosci. 5, 813-820 (2005).

8 de Jong, S.J., De Smedt, S.C., Wahls, M.W.C., Demeester, J., Kettenes-van der Bosch, J.J. \& Hennink, W.E. Novel self-assembled hydrogels by stereocomplex formation in aqueous solution of enantiomeric lactic acid oligomers grafted to dextran. Macromolecules 33, 3680-3686 (2000).

9 Burdick, J.A., Philpott, L.M. \& Anseth, K.S. Synthesis and characterization of tetrafunctional lactic acid oligomers: a potential in situ forming degradable orthopedic biomaterial. J. Polym. Sci. A Polym. Chem. 39, 683-692 (2001).

10 Hill, G.T.H., Irvine, D.J., Thurecht, K.J., Botting, C.H., Williamson, S. \& Cole-Hamilton, D.J. Preparation of sodium-capped poly(lactic acid) oligomers by catalytic initiation with a sodium $\alpha-, \beta-$, or $\gamma$-hydroxyacids. Macromolecules 43, 185-192 (2010).

11 Coullerez, G., Lowe, C., Pechy, P., Kausch, H.H. \& Hilborn, J. Synthesis of acrylate functional telechelic poly(lactic acid) oligomer by transesterification. J. Mater. Sci. Mater. Med. 11, 505-510 (2000).

12 van den Berghe, H., Coudane, J. \& Vert, M. Isocyanate-terminated lactic acid oligomers as a new means to conjugate functional drugs or polymers with bioresorbable hydrophobic segments. J. Bioact. Comp. Polym. 22, 637-650 (2007).

13 Perego, G., Cella, G.D. \& Bastioli, C. Effect of molecular weight and crystallinity on poly(lactic acid) mechanical properties. J. Appl. Polym. Sci. 59, 37-43 (1996).

14 Coupin, T., Coszach, P. \& Hottois, D. Isotactic polylactic acid and method for producing same. US Patent Appl. 20110319588.

15 Shaver, M.P. \& Cameron, D.J.A. Tacticity control in the synthesis of poly(lactic acid) polymer stars with dipentaerythritol cores. Biomacromolecules 11, 3673-3679 (2010).

16 Cameron, D.J.A. \& Shaver, M.P. Control of thermal properties and hydrolytic degradation in poly(lactic acid) polymer stars through control of isospecificity of polymer arms. J. Polym. Sci. A Polym. Chem doi:10.1002/pola.25927.

17 Okihara, T., Tsuji, M., Kawaguchi, A. \& Katayama, K. Crystal structure of stereocomplex of poly(L-lactide) and poly(D-lactide). J. Macromol. Sci. Phys. B30, 119-140 (1991).

18 Ikada, Y., Jamshidi, K., Tsuji, H. \& Hyon, S.-H. Stereocomplex formation between enantiomeric poly(lactides). Macromolecules 20, 904-906 (1987).

19 Tsuji, H. \& Ikada, Y. Stereocomplex formation between enantiomeric poly(lactic acids). 9. Stereocomplexation from the melt. Macromolecules 26, 6918-6926 (1993).

20 Tsuji, H. \& Ikada, Y. Stereocomplex formation between enantiomeric poly(lactic acid)s. 6. Binary blends from copolymers. Macromolecules 25, 5719-5723 (1992).

$21 \mathrm{Li}$, L., Zhong, Z., de Jeu, W.H., Dijkstra, P.J. \& Feijen, J. Crystal structure and morphology of poly(L-lactide- $b$-D-lactide) diblock copolymers. Macromolecules 37, 8641-8646 (2004)

22 Fukushima, K. \& Kimura, Y. A novel synthetic approach to stereo-block poly(lactic acid). Macromol. Symp. (2005)224, 133-143. 
23 Fukushima, K., Furuhashi, Y., Sogo, K., Miura, S. \& Kimura, Y. Stereoblock poly(lactic acid): synthesis via solid-state polycondensation of a stereocomplexed mixture of poly(L-lactic acid) and poly(D-lactic acid). Macromol. Biosci. 5, 21-29 (2005).

24 Bero, M., Kasperczyk, J. \& Jedlinski, Z. J. Coordination polymerization of lactides, 1. Structure determination of obtained polymers. Makromol. Chem. 191, 2287-2296 (1990).

25 Kricheldorf, H.R., Boettcher, C. \& Tonnes, K. Polylactones: 23. polymerization of racemic and meso $\mathrm{D}, \mathrm{L}-$-lactide with various organotin catalysts-stereochemical aspects. Polymer 33, 2817-2824 (1992).

26 Kasperczyk, J.E. Microstructure analysis of poly(lactic acid) obtained by lithium tertbutoxide as initiator. Macromolecules 28, 3937-3939 (1995).

27 Thakur, K.A.M., Kean, R.T. \& Hall, E.S. High-resolution ${ }^{13} \mathrm{C}$ and ${ }^{1} \mathrm{H}$ solution NMR study of poly(lactide). Macromolecules 30, 2422-2428 (1997).

28 Kasperczyk, J.E. HETCOR NMR study of poly(rac-lactide) and poly(meso-lactide). Polymer 40, 5455-5458 (1999).

29 Chisholm, M.H., Iyer, S.S., McCollum, D.G., Pagel, M. \& Werner-Zwanziger, U. Microstructure of poly(lactide). phase-sensitive HETCOR spectra of poly(mesolactide), poly(rac-lactide), and atactic poly(lactide). Macromolecules 32, 963-973 (1999).

30 Zell, M.T., Padden, B.E., Paterick, A.J., Thakur, K.A.M., Kean, R.T., Hillmyer, M.A. \& Munson, E.J. Unambiguous determination of the ${ }^{13} \mathrm{C}$ and ${ }^{1} \mathrm{H}$ NMR stereosequence assignments of polylactide using high-resolution solution NMR spectroscopy. Macromolecules 35, 7700-7707 (2002).

31 Suganuma, K., Horiuchi, K., Matsuda, H., Cheng, H.N., Aoki, A. \& Asakura, T. Stereoregularity of poly(lactic acid) and their model compounds as studied by NMR and quantum chemical calculations. Macromolecules 44, 9247-9253 (2011).

32 Bax, A. \& Subramanian, S. Sensitivity-enhanced two-dimensional heteronuclear shift correlation NMR spectroscopy. J. Magn. Reson. 67, 565-569 (1986).

$33 \mathrm{Bax}, \mathrm{A}$. \& Summers, M.F. ${ }^{1} \mathrm{H}$ and ${ }^{13} \mathrm{C}$ Assignments from sensitivity-enhanced detection of heteronuclear multiple-bond connectivity by 2D multiple quantum NMR. J. Am. Chem. Soc. 108, 2093-2094 (1986).

34 Summers, M.F., Marzilli, L.G. \& Bax, A. Complete proton and carbon-13 assignments of coenzyme B12 through the use of new two-dimensional NMR experiments. J. Am. Chem. Soc. 108, 4285-4294 (1986).

35 Carbone, P., Ragazzi, M., Tritto, I., Boggioni, L. \& Ferro, D.R. Ab initio molecular modeling of ${ }^{13} \mathrm{C}$ NMR chemical shifts of polymers. 2. propene-norbornene copolymers. Macromolecules 36, 891-899 (2003).

36 Boggioni, L., Bertini, F., Zannoni, G., Tritto, I., Carbone, P., Ragazzi, M. \& Ferro, D. R. Propene-norbornene copolymers: synthesis and analysis of polymer structure by ${ }^{13} \mathrm{C}$ NMR spectroscopy and ab initio chemical shift computations. Macromolecules 36 , 882-890 (2003).

37 Wu, W., Li, W., Wang, L., Zhang, P. \& Zhang, J. Density functional theory study on lactides: geometries, IR, NMR and electronic spectra. Theochem. 816, 13-19 (2007).

38 Kang, Y.K. \& Byun, B. Conformational preferences and cis-trans isomerization of Llactic acid residue. J. Phys. Chem. B 112, 9126-9134 (2008).

39 Inai, Y. \& Ogawa, H. [Theoretical studies on conformational features of poly(lactic acid) chain containing a racemic unit]. Kobunshi Ronbunshu 67, 214-223 (2010).
40 McAliley, J.H., O’Brien, C.P. \& Bruce, D.A. Continuum electrostatics for electronic structure calculations in bulk amorphous polymers: application to polylactide. J. Phys. Chem. A 112, 7244-7249 (2008).

41 Sadlej, J., Dobrowolski, J.C., Rode, J.E. \& Jamroz, M.H. DFT study of vibrational circular dichroism spectra of D-lactic acid water complexes. Phys. Chem. Chem. Phys. 8, 101-113 (2006)

42 Becke, A.D. Density-functional thermochemistry. III. The role of exact exchange. J. Chem. Phys. 98, 5648 (1993).

43 Dickinson, B.N. The normal state of the hydrogen molecule-ion. J. Chem. Phys. 1, 317 (1933).

44 Frisch, M.J., Pople, J.A. \& Binkley, J.S. Self-consistent molecular orbital methods 25 supplementary functions for gaussian basis sets. J. Chem. Phys. 80, 3265 (1984).

45 Clark, T., Chandrasekhar, J., Spitznagel, G.W. \& Schleyer, P.v.R. Efficient diffuse function-augmented basis sets for anion calculations. III. The $3-21+G$ basis set for first-row elements, Li-F. J. Comp. Chem. 4, 294-301 (1983).

46 Schafer, A., Horn, H. \& Ahlnichs, R. Fully optimized contracted Gaussian basis sets for atoms Li to Kr. J. Chem. Phys. 97, 2571-2577 (1992).

47 Schafer, A., Huber, C. \& Ahlnichs, R. Fully optimized contracted Gaussian basis sets of triple zeta valence quality for atoms Li to Kr. J. Chem. Phys. 100, 5829-5835 (1994).

48 Becke, A.D. Density-functional thermochemistry. III. The role of exact exchange. J. Chem. Phys. 98, 5648-5652 (1993).

49 Woon, D.E. \& Dunning, Jr. T.H. Gaussian basis sets for use in correlated molecula calculations. III. The atoms aluminum through argon. J. Chem. Phys. 98, 1358-1371 (1993).

50 Kendall, R.A., Dunning, Jr. T.H. \& Harrison, R.J. Electron affinities of the first-row atoms revisited. Systematic basis sets and wave functions. J. Chem. Phys. 96, 67966806 (1992)

51 Dunning, Jr. T.H. Gaussian basis sets for use in correlated molecular calculations. I. The atoms boron through neon and hydrogen. J. Chem. Phys. 90, 1007-1023 (1989).

52 Peterson, K.A., Woon, D.E. \& Dunning, Jr. T.H. Benchmark calculations with correlated molecular wave functions. IV. The classical barrier height of the $\mathrm{H}+\mathrm{H}_{2} \rightarrow \mathrm{H}_{2}+\mathrm{H}$ reaction. J. Chem. Phys. 100, 7410-7415 (1994).

53 Wilson, A.T., Mourik, T.V. \& Dunning, Jr. T.H. Gaussian basis sets for use in correlated molecular calculations. VI. Sextuple zeta correlation consistent basis sets for boron through neon.. J. Mol. Struct. (Theochem) 388, 339-349 (1996).

54 London, F. [Théorie quantique des courants interatomiques dans les combinaisons aromatiques]. J. Phys. Radium 8, 397-409 (1937).

55 McWeeny, R. Perturbation theory for the Fock-Dirac density matrix. Phys. Rev. 126, 1028-1034 (1962)

56 Ditchfield, R. Self-consistent perturbation theory of diamagnetism I. A gauge- invariant LCAO method for N.M.R. chemical chifts. Mol. Phys. 27, 789-807 (1974).

57 Wolinski, K., Hilton, J. F. \& Pulay, P. Efficient implementation of the gaugeindependent atomic orbital method for NMR chemical shift calculations. J. Am. Chem. Soc. 112, 8251-8260 (1990).

58 Cheeseman, J.R., Trucks, G.W., Keith, T.A. \& Frisch, M.J. A comparison of models for calculating nuclear magnetic resonance shielding tensors. J. Chem. Phys. 104, 5497-5509 (1996). 